\title{
CONHECENDO SEUS PRÓPRIOS TALENTOS: JOVENS DE ESCOLAS PÚBLICAS EM INSTITUIÇŌES DE PESQUISA NO RIO DE JANEIRO
}

\author{
Ana Maria AmÂncio* \\ Rosa Maria Corrêa das Neves*
}

\begin{abstract}
RESUMO: Intervençôes educativas com a juventude merecem ser sempre analisadas e é isto a que nos propomos neste artigo. Trazemos uma reflexão que inicia por uma demarcação fundamental sobre como entendemos o jovem. Seguimos pela apresentação de um projeto específico - Jovens Talentos -, iniciação à ciência dirigida à parcela de estudantes da escola pública no estado do Rio de Janeiro, para que realizem atividades científicas, sob orientação de um pesquisador, freqüentando um determinado laboratório. Procuramos analisar como os que passam por essa experiência indicam compreendê-la. Essa iniciativa foi percebida como fundamental em questôes relativas à independência e à autonomia do estudante, mostrando a relevância de ações educativas dirigidas a jovens.
\end{abstract}

Palavras-chave: Juventude. Autonomia. Iniciação à pesquisa.

\section{KNOWING ONE'S OWN TALENTS: PUBLIC SCHOOL YOUNGSTERS IN THE RESEARCH INSTITUTIONS OF Rio DE JANEIRO}

ABSTRACT: Educational interventions related to youth always deserve being analyzed. This paper thus brings forward a reflection that begins with a fundamental delimitation of how we understand youngsters. It then presents a specific project Jovens Talentos (Young Talents) - that initiates the students of public schools in the State of Rio de Janeiro to science. They perform scientific activities under the direction of a researcher

\footnotetext{
* Pesquisadora do Programa de Computação Científica da Fundação Oswaldo Cruz (Fiocruz).E-mail:amma@uol.com.br

** Professora da Graduação em Pedagogia da Universidade Estácio de Sá. E-mail: rosamcn@uol.com.br
} 
and use a laboratory. We tried to analyze how the students that underwent this experience understand it. This initiative is held as fundamental in some issues related to the independence and autonomy of the student, which shows the importance of educational actions directed to youngsters.

Key words: Youth. Autonomy. Initiation to research.

\section{Introdução}

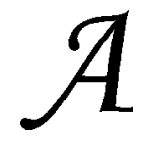

juventude e os temas relativos a ela têm sido preocupação constante na mídia e nos meios acadêmicos. Questóes como violência, iniciação sexual, adição a drogas, definição profissional, entre outras, cercam e configuram a problemática do jovem, tornam-se notícia, são alvo de ações concretas e procuram ser entendidas por pais, sociólogos, antropólogos, profissionais de educação, de saúde, enfim entre todos que tenham interesses específicos neste grupo social.

Identificamos estudos demográficos que apontam o Brasil recentemente ter vivido uma "onda jovem" - registrou-se no ano 2000 uma das maiores proporçōes de jovens da história demográfica brasileira (Madeira \& Rodrigues, 1998, p. 430). Certamente isso é um dos fatores que explicam um interesse mais intenso pela juventude: há mais jovens tomando parte da cena.

Intervenções educativas com a juventude merecem ser sempre analisadas e é isto a que nos propomos neste artigo. Trazemos uma reflexão que inicia por uma demarcação fundamental sobre como entendemos o jovem. Seguimos pela apresentação de um projeto específico - Jovens Talentos -, iniciação à ciência dirigida a parcela de estudantes da escola pública no estado do Rio de Janeiro, e sobre como os que passam por essa experiência indicam percebê-la. Concluímos por alguns comentários sobre o que esse projeto pode contribuir para o desenho de ações educativas dirigidas a jovens.

Breve leitura sobre a juventude

Para a Organização Mundial de Saúde, a juventude é tratada como "processo sociocultural demarcado pela preparação dos indivíduos para assumirem o papel de adulto na sociedade, no plano familiar e profissional" (Minayo, 1999, p. 13) e não propriamente como uma faixa etária de vida. A identificação dos jovens reflete momentos 
distintos em que definem e constroem os papéis que vão assumir num futuro que se inicia brevemente - a vida adulta.

O estudo histórico da juventude dirige-nos o olhar para períodos não tão longínquos da história humana em que o futuro não representava um mistério - havia poucas possibilidades de existência e, entre as que havia, não era habitual que fosse prerrogativa do próprio sujeito a definiçãa de seu futuro. Cônjuges, profissóes, patrimônio, religião, gostos, uns e outros, mais e menos já haviam sido determinados e cabiam ser respeitados.

Idealmente, segundo os padrões ocidentais modernos, as definições de vida dão-se mediante escolhas em que a adesão aos papéis de adulto não é rigidamente estabelecida pelos grupamentos sociais de que o sujeito participa - quaisquer que sejam (família, escola, classe social) -, mas partem de um posicionamento que se deseja mais individual e autônomo. As decisões passam a incluir de maneira mais significativa uma identificação volitiva do sujeito.

Vive-se a partir de então um outro espaço, um outro tempo. Imagina-se que todos os indivíduos se preparem para encontrar o seu lugar nas sociedades. Obriga-se que, em algum momento das trajetórias de vida, a vivência das definiçõos seja processada em termos de um adulto possível e desejado. Vê-se a partir de então um jovem mais ativo que elabora e dedica tempo para construir o seu próprio futuro.

E só nas camadas letradas ${ }^{1}$ iremos encontrar já formado o embrião da idéia da juventude enquanto moratória, isto é, a de uma economia de vida baseada em uma renúncia temporária na esperança de uma carreira futura e de melhores oportunidades financeiras, idéia que encontra seu fundamento social num período de "formação" que dura muitos anos, em grande parte livre da necessidade de se manter e que hoje já se tornou demasiado habitual. (Schindler, 1996, p. 271)

Ganha força então a juventude, entendida como categoria social marcada por escolhas, expectativas, crises que constituem os processos decisórios em termos das mudanças esperadas.

Assim, no plano individual, a juventude deve ser considerada uma fase crucial para a formação e a transformação de cada um, quer se trate da maturação do corpo e do espírito, quer no que diz respeito às escolhas decisivas que preludiam a inserção definitiva da vida na comunidade. Deste ponto de vista, a juventude é efetivamente o momento das tentativas sem futuro, das vocações ardentes mas mutáveis, da "busca" (a do 
cavaleiro medieval) e das aprendizagens (profissionais, militares e eróticas) incertas, sempre marcadas por uma alternância de êxitos e fracassos. (Levi \& Schmitt, 1996, p. 11)

O ângulo sob o qual temos olhado os jovens sublinha sobretudo o dinamismo e a mudança como típicos deste grupo social. Dinamismo que busca concretizar e construir a identidade de adulto, constantemente solicitada e na qual se encontram empenhados.

É possível localizar, a partir da consolidação da modernidade, uma idéia geral de juventude que não se circunscreve a um grupo social restrito, a um tempo ou a um espaço mas, como nos dizem Levi \& Schmitt (1996), por uma "nova percepção - globalizante, nacional e depois internacional - da juventude, de seus problemas, de seus modelos (p. 16)". Essa percepção adquire vigor a partir do desenvolvimento dos Estados modernos e da dilatação das bases territoriais que extrapolam a aldeia ou o bairro, conformando grupos sociais mais ampliados.

Nos dias atuais, entretanto, é mais difícil admitir uma expressão única e geral de juventude. O conceito da pós-modernidade coloca-nos a heterogeneidade como traço cultural que privilegia a diferença. Isto significa que a juventude assume diferentes padrôes culturais que são localizados, fragmentados e singulares, o que representa referir-se a jovens de diferentes grupos, diferentes tribos. Semelhante reflexão encontramos em Madeira \& Rodrigues (1998, p. 453), que comentam sobre as disparidades de vida de jovens a partir das diferentes classes sociais no Brasil:

(...) é tal a heterogeneidade de situaçôes que vivenciam os jovens no Brasil de hoje que é difícil pensá-los como categoria única. Além da faixa etária, poucas são as semelhanças tanto na vivência cotidiana como nos projetos de vida. Ou seja, existiriam semelhanças entre, por exemplo, a juventude universitária e a juventude camponesa? Entre a juventude universitária e o jovem camponês?

O que procuramos argumentar aqui é que, apesar (ou para além) destas diferenças que efetivamente existem, os jovens, independente de sua condição socioeconômica, não só apresentam, mas sobretudo cultivam uma identidade ou uma marca da "juventude". A juventude é uma espécie de moratória entre a infância e a vida adulta.

Pensamos que a diversidade de modos de ser jovem inclui não somente traços de classe socioeconômica mas também de valores culturais. E tais quais as autoras, admitimos como possível 
uma idéia geral da juventude, para além das diferenças. Circunscrevemos assim nossa leitura um tanto simplificada sobre o jovem, a fim de caracterizá-lo como um sujeito empenhado em tornar-se, mudar, experimentar, decidir, escolher, enfim preparar-se rumo à vida adulta. Partimos desta conceituação para seguirmos na apresentação e análise do projeto Jovens Talentos, que envolve estudantes de escolas públicas em processo de iniciação à ciência, buscando entender como incorporam essa experiência de iniciação à ciência aos seus repertórios de vida.

\section{Explicando o projeto Jovens Talentos}

O projeto Jovens Talentos ${ }^{2}$ tem como proposta catalisar o potencial científico e tecnológico, localizado no estado do Rio de Janeiro, ${ }^{3}$ procurando integrá-lo num projeto pedagógico voltado para estudantes do ensino médio/técnico. Diversas instituiçôes que se dedicam a pesquisas, ${ }^{4}$ reconhecidas em nível nacional e internacional por seus trabalhos, vêm aderindo ao projeto, que abrange áreas de conhecimento como matemática, física, química, biologia, computação científica, engenharias, agropecuária, geologia, entre outras. As instituições disponibilizam laboratórios para a iniciação científica de jovens estudantes.

A seleção de candidatos aos estágios busca alunos com interesse e curiosidade científica, bom nível de escolaridade e responsabilidade, além de uma personalidade marcada pela criatividade, ousadia e autonomia. O jovem deve se encontrar na faixa etária entre 15 e 18 anos e estar matriculado na $2^{\text {a }}$ série do nível médio da rede pública no estado do Rio de Janeiro. Durante o período em que se dedicam ao projeto, os jovens recebem uma bolsa, no valor aproximado de meio salário mínimo, pensada como forma de garantir o ingresso de jovens que sem este auxílio não poderiam se candidatar.

Os jovens realizam atividades científicas, sob orientação de um pesquisador, freqüentando em dois turnos semanais um laboratório. Há um estágio inicial com seis meses de duração, estando sob a responsabilidade da coordenação do projeto a seleção dos candidatos. Após essa primeira fase, aqueles que demonstrarem grande afinidade com a atividade científica podem candidatar-se à renovação para desenvolver projetos de pesquisa por mais 12 (doze) meses, ingressando no estágio avançado. 
Para ingressar no estágio avançado o estudante deve ser recomendado pelo seu orientador e apresentar um plano de estudos que evidencie uma investigação caracterizando pesquisa científica. $\mathrm{O}$ desenvolvimento do estagiário é acompanhado pela coordenação do projeto por meio de vários instrumentos criados para este fim. No estágio avançado há um documento de avaliação preenchido pelo orientando e apreciado pelo orientador. Destacamos deste material dois registros que mostram o entusiasmo dos pesquisadores, que provavelmente vão proporcionar novos caminhos, novas chances para esses estudantes.

A aluna mostrou-se muito responsável e entusiasta. Realizou seu projeto com autonomia e criatividade. Recomendo a aluna a futuros apoios para pesquisa e formação de pesquisadores. (C.T.C. - 25/10/2001)

A bolsista apresentou ótimo desempenho, tendo atingido inclusive autonomia ao longo do estágio, tomando decisões e apresentando sugestões válidas para o desempenho do projeto. (F.R.V.S. - 3/9/2001)

O projeto vem crescendo e a cada ano mais estudantes e pesquisadores participam, ${ }^{5}$ confirmando uma possibilidade de articulação entre a pesquisa e o ensino. Alguns jovens têm publicado artigos científicos em revistas internacionais, participado de congressos no Brasil e no exterior e alcançado prêmios em concursos nacionais.

\section{Intenções e organização do estudo}

Nossa reflexão se singulariza por termos a oportunidade do contato freqüente com parte da juventude de que tem se falado. ${ }^{6}$ Percebemos este fato como próprio de muitas pesquisas realizadas na área da educação, em que os pesquisadores estão mergulhados na mesma realidade que pretendem compreender. Falar sobre o jovem, portanto, não representa aqui um discurso pouco comprometido mas, muito ao contrário, um percurso de trabalho e pesquisa que, recusando a adoção de uma postura prescritiva, encaminha um movimento em torno das falas e atitudes dos jovens e das teorias que elegemos para melhor compreendê-lo.

Anterior a este estudo mais intenso e sistemático, já reuníamos avaliações e considerações dos estudantes com relação ao projeto, seja pela promoção de encontros periódicos ou ainda por avaliaçôes registradas em instrumentos pedagógicos. De modo geral, 
extraíamos daí uma confirmação dos jovens de que suas vivências nos laboratórios se mostravam enriquecedoras.

$\mathrm{Na}$ intenção de aprofundarmos as afirmações desses estudantes, buscamos por este estudo explorar e quando possível precisar em que dimensões e direçóes o projeto Jovens Talentos colabora nas tomadas de decisão e definições de suas vidas.

Em um primeiro momento, definimos que nos interessava explorar alguns temas que conformam a problemática da juventude e que tivessem ao mesmo tempo relação com a iniciação à ciência - o estágio como experiência de vida, como vivência de relacionamentos, como orientação à profissão -, ao trabalho e ao estudo. Estas temáticas se constituíram como questões abertas de um questionário a ser preenchido individualmente.

Numa segunda delimitação, selecionamos como sujeitos para o estudo aqueles jovens que se encontravam em fase de conclusão do estágio avançado no mês de agosto de 2001, o que representou 48 estudantes. A coleta dos dados ocorreu de modo que se encaminhasse uma reflexão individual e também provocasse o diálogo entre os próprios sujeitos e as pesquisadoras. Dessa forma, os concludentes foram convocados a estar presentes em reuniōes organizadas para este fim, comparecendo um total de 31 jovens. No primeiro momento, pedimos que respondessem ao questionário. A identificação no instrumento foi dispensada para que o constrangimento a alguma crítica fosse minimizado. Num segundo momento do encontro, colocamos em discussão as respostas dadas aos temas.

A apresentação do que segue se centra sobretudo no que os jovens indicam de forma recorrente como o que há de novo em suas vidas, que entendem como sendo resultado de sua passagem pelo projeto Jovens Talentos, e das relações que estabelecem a partir de então sobre a escolha profissional, o trabalho, os estudos e sobre a própria identidade do jovem. Acrescentamos à analise a problematização do que encontramos como respostas ante os estudos anteriores que buscam caracterizar a juventude brasileira e carioca.

\section{Revelando a capacidade do jovem}

A experiência do estágio tem um significado particular para cada jovem e entre eles alcança várias dimensões em suas vidas. Os jovens confirmam-nos suas vivências nos laboratórios como significativas com rela- 
ção a mudanças de atitudes, perspectivas, definições que extrapolam os espaços da profissão e do estudo, ainda que se reconheça que é em torno destes dois interesses em particular que muitos buscam o projeto.

Há diversos depoimentos que apontam o projeto como "a melhor experiência de vida”. Alguns exemplos:

Ele [o projeto] simplesmente revolucionou a minha vida, me proporcionou um crescimento individual fantástico. Posso dizer que tive uma das maiores e melhores experiências da minha vida.

Corri muito atrás deste projeto, e por isso digo que até agora foi a melhor experiência de minha vida. Contudo, acredito que tive capacidade, e por este motivo não irei desanimar nas barreiras que ainda estarão por vir.

Ainda que o êxito do projeto entre os estagiários ganhe diversas traduções - profissional, social, científico -, existe uma confirmação de que tomar parte do projeto representa a possibilidade que esses estudantes têm de revelar o potencial, a capacidade do jovem. Encontram uma oportunidade de efetiva realização, de exibição de potencialidades e o reconhecimento de qualidades que se encontravam para eles mesmos ignoradas.

Este foi um momento de minha vida que posso afirmar que será inesquecível. Pois me mostrou a capacidade e o desempenho que tenho e desenvolveu minhas habilidades na área científica.

A importância é muito grande em minha vida. Pois descobri um potencial para a área de física que não sabia que tinha. Aprendi a ter mais disciplina e organização para desenvolver projetos, a estabelecer uma relação profissional com o orientador.

Muitos chegam a referir-se à conquista de autoconfiança, independência e autonomia.

A sua vida muda. $\mathrm{Na}$ escola, as pessoas passam a admirar você, e não só nela, como na família, com os amigos e etc.

E adorei a experiência de ter meu próprio dinheiro pago através do meu esforço, da minha competência.

Mais do que uma oportunidade de aprendizado da ciência, é uma vivência que permite o descobrimento de si mesmo, das próprias possibilidades, um encontro consigo mesmo vivido de uma forma bastante satisfatória. 
O projeto não tem como objetivo ser um estágio profissionalizante, entendido como campo de práticas para aplicação de conhecimentos teóricos adquiridos na escola, o que caracteriza os cursos de formação técnica. Não é este o caso aqui. Entretanto, os estudantes reconhecem uma expressiva contribuição no desempenho escolar, que se torna diferente. Dizem que adquirem novas atitudes em sua trajetória - sobretudo têm mais interesse nos estudos. Apontam também disciplina, atenção, criatividade, prazer e responsabilidade como ganhos efetivos.

O conceito e a posição em relação aos estudos mudaram. Passei a criar e não só consumir conhecimento. Passei a enxergar os estudos também como uma forma de prazer.

Estou me interessando mais em aprender, vejo agora que é um mundo mágico.

Os estudantes, além de apontarem os estágios como uma vivência significativa que os valoriza, reconhecem que o que realizam repercute em seu futuro profissional também de forma muito positiva. Muitos deles, quando questionados sobre as possíveis relaçôes entre o projeto e a escolha profissional, indicam que se questionar sobre uma profissão já fazia parte de suas vidas - a escolha profissional já era vivida como uma certeza para uns ou como dúvida para outros. Entretanto o que sobressai, além de que o projeto colabore para uma definição profissional, é o fato de que essa experiência amplia horizontes de vida. Esta compreensão, na percepção dos estudantes, segue por basicamente três dimensões - ao passo que alguns passam a conhecer uma nova área de estudos, há aqueles que passam a colocar como possibilidade de vida a graduação ou ainda a atividade de pesquisa. Vemos aqui mais uma vez que esses jovens extrapolam o aprendizado de um certo conteúdo nessa vivência para incorporar questôes mais gerais com relação à busca profissional.

Não temos ainda organizados os dados relativos ao ingresso de participantes do projeto em universidades, porém é importante lembrar que, para além da química, da física ou da biologia, percebem estar situados num campo profissional que, sublinhe-se, está em geral situado fora das possibilidades de acesso do jovem da escola pública. A pesquisa no Brasil e no estado do Rio de Janeiro é largamente desenvolvida no setor público, por universidades públicas e são 
essas instituições em sua grande parte que cooperam no projeto. Ingressam nessas universidades, majoritariamente, jovens das classes médias e altas que tiveram acesso a uma boa escola em suas vidas, em razão dos exames vestibulares restritivos e altamente seletivos.

Os sujeitos de nossa pesquisa percebem isso. Ainda que não se refiram de modo explícito a esta realidade, alguns comentam que o estágio é oportunidade de estar num ambiente de alta qualidade, convivendo com profissionais reconhecidos, importantes, "pessoas avançadas". Alguns passam a entender o ensino superior como uma possibilidade que até então parecia não estar colocada.

A faculdade/universidade era uma "coisa de outro mundo". Não sabia que eu poderia estar aqui quase todo dia sem cursar a UERJ. E para entrar aqui, para mim, era muito difícil, mas o CECIERJ me ajudou e hoje estou aqui.

Me ajudou do ponto de vista que uma faculdade, um diploma na mão vale muito mais.

Por seus objetivos, o projeto não se coloca como uma experiência de trabalho. Se assim fosse, exigiria um determinado desempenho em contrapartida com um salário. Os estágios no caso do projeto Jovens Talentos não se apresentam dessa forma. Representam um aprendizado amplo no campo das ciências, descomprometido com qualquer resultado efetivo que não a própria aprendizagem dos estudantes.

Ainda que os estágios não se coloquem como uma vivência de trabalho, não se pode negar que supõem uma experiência profissional - os estudantes adentram um ambiente de trabalho. Essa compreensão é expressa por parte dos jovens quando, em suas respostas, afirmam que a vivência do projeto consiste numa preparação, particularmente no que diz respeito a atitudes para o trabalho - em especial seriedade e responsabilidade.

Alguns chegam a concluir que o projeto conforma uma primeira experiência profissional, o que é muito importante para o jovem que, em geral, tem dificuldade de obter o primeiro emprego em razão da falta de experiências antecedentes.

Uma das perversidades da economia globalizada é a precarização do trabalho $^{7}$ (desemprego estrutural, subemprego, desproteção previdenciária do trabalhador), que afeta diretamente o jovem quando confrontado com seu presente e futuro. Se não há perspectiva concreta de autonomia, emprego e rendimento, a desesperança é conseqüência imediata e terreno fértil para situações de risco e violência. A 
ausência de um espaço de realização legítima pode levar o jovem a perceber a sociedade de forma ameaçadora, pois não lhe reserva nenhuma segurança e proteção para o experimentar, o que entendemos como vital para toda a juventude.

Por esta razão, ganha também valor a caracterização dos estudantes sobre este "ambiente de trabalho" que é o laboratório e a relação que aí estabelecem. Tudo se faz por uma interação que é amistosa, de respeito e cooperação. Há um encontro com o outro que o vê como igual, o que é também bastante satisfatório.

As apreciações dos estagiários com relação ao projeto são extremamente positivas. Tanto assim que muitos recomendam a extensão do projeto a um número maior de jovens. Para um sujeito que se encontra numa fase de vida em que a operação de definiçõoes é fundamental e é exatamente o que permite construir sua singularidade, escolher, decidir e experimentar são movimentos cruciais que não se dão de forma isolada e individual, mas se realizam num determinado contexto. Concordando com Berger (1986), entendemos que o processo de "identificação não é uma coisa preexistente; é atribuída em atos de reconhecimento social” (p. 113). Assim, a experiência do projeto ganha mais em significado, pois o reconhecimento positivo em torno de si mesmo, que é certamente uma conquista particular, individual e singular, só é possível se vivido num ambiente em que se é valorizado e prestigiado.

\section{Alguns pensamentos}

Como já dissemos, o projeto é destinado aos estudantes da Rede Pública Estadual do Rio de Janeiro, matriculados no ensino médio/ técnico, portanto estes fazem parte de um grupo que na maioria das vezes fica excluído das melhores oportunidades, aquelas que mais proporcionam desenvolvimento e progresso intelectual.

Por tudo que analisamos neste artigo, o aluno que passa pela experiência do projeto Jovens Talentos, precocemente inicia um forte processo de identidade gerando conduta de independência. Esse estudante passa a acreditar nele mesmo, adquire segurança, sente-se fortalecido e conquista atitudes de autonomia.

Durante o período de estágio eles adquirem novos conhecimentos e freqüentam eventos que resultam num comportamento diferenciado dos demais adolescentes, colegas da sua própria escola. Mani- 
festam grande entusiasmo e interesse pelas atividades intelectuais, pode-se mesmo falar em prazer. Esse é um dos pontos para o qual chamamos atenção e que convidamos à reflexão: estudar, ensinar, ir à escola, ler etc., tudo isso pode ser divertido; o aluno deveria desejar aprender, gostar de estudar.

Observamos que a vivência nesse estágio de iniciação científica é muito especial pelo fato de solicitar um comportamento de muita responsabilidade, muito compromisso e conduta independente. Sabese que esses fatores geram autonomia e crescimento pessoal. Em muitos casos a experiência chega a elucidar os caminhos de estudo, a proporcionar uma colaboração efetiva no despertar da vocação e até mesmo na definição pessoal profissional. Escolher profissão para os jovens é uma questão diretamente ligada à conquista da sua própria liberdade, do seu sucesso e do status na sociedade em que estão inseridos. Com base em criteriosa pesquisa sobre a juventude carioca, Minayo (1999, p. 216) afirma: "Para todos os grupos sociais, as questões do emprego e da profissionalização são vinculadas ao sucesso, à fama e ao dinheiro, o que aparece como uma forte estrutura de relevância na projeção do futuro dos jovens". E ainda: "Como se pode constatar, a maioria dos jovens pertencentes às classes médias e altas e populares considera que o sucesso dependerá de sua aplicação nos estudos, de seus esforços e de seu trabalho" (p. 218).

É portanto uma preocupação constante entre os jovens aproveitar as oportunidades para conseguir emprego, trabalho. Neste cenário percebemos que os estudantes do projeto valorizam muito estar num ambiente como o das universidades ou outros locais de pesquisa como as instituições de Ciência \& Tecnologia. Uma das contribuições que vemos pelo Jovens Talentos é que este se organiza a partir de espaços já constituídos, de relevância social, contribuindo assim para a efetiva inclusão.

No Brasil as injustiças sociais são grandes, causando sérios problemas na formação do cidadão, atingindo especialmente o jovem estudante. Segundo Minayo (ibid., p. 17):

O país possui uma das piores distribuições de renda do mundo, tendo como conseqüência profundas desigualdades socioeconômicas, das quais as crianças, os adolescentes e os jovens são as maiores vítimas. Apresenta graves problemas educacionais, grandes desigualdades nas formas de adoecimento e morte, além de sérios entraves nas questôes de moradia, oportunidades de trabalho e de lazer. Assim, esses jovens vivenciam e representam o ser jovem 
de formas marcadamente distintas, influenciados por diferentes inserções sociais que conduzem a oportunidades diferenciadas e seletivas de acesso a bens materiais e culturais.

Para gerar mudanças relevantes neste quadro há que se pensar em novas propostas, novos caminhos que indiquem a construção de políticas educacionais que façam efetivas transformações na educação em nosso país. Uma maior interação entre a escola e a universidade pode contribuir para um ensino de qualidade, atendendo às necessidades e questões do mundo contemporâneo. A integração ensino e pesquisa talvez possa ser o ponto de partida para se alcançar mudanças que proporcionem a democratização da escola. Nessa trajetória a educação deve ter como meta a formação do homem integral, possuidor de independência e capacidade para tecer críticas, qualidades indispensáveis para se fazer frente às exigências do desenvolvimento científico e tecnológico da atualidade.

Nosso pensamento é que os estudantes se entendam com novas condiçôes, novas possibilidades, consigam ser mais respeitados, ampliando assim a perspectiva de se tornarem verdadeiros cidadãos. A nossa crença é a de que eles se sintam incluídos nesta sociedade que parecia tão cruel, tão sem esperanças, sem perspectivas.

\section{Recebido em setembro de 2002 e aprovado em fevereiro de 2003.}

\section{Notas}

1. Para Schindler (1996, p. 271) a vida escolar, obrigatória a partir do início do século XIX, demarca uma distinção clara entre infância e juventude no momento da conclusão dos estudos, do início da aprendizagem e ingresso no mundo do trabalho.

2. Projeto com início em 1999, da Fundação Centro de Ciências e Educação Superior do Estado do Rio de Janeiro (CECIERJ), conta com apoio da Fundação Carlos Chagas Filho de Amparo à Pesquisa do Estado do Rio de Janeiro (FAPERJ), que promove a iniciação científica de estudantes do ensino médio/técnico da rede pública estadual de educação em instituiçôes de Ciência \& Tecnologia.

3. Entre os anos de 1999 e 2002 o projeto abrangeu quatro diferentes cidades no estado do Rio - Arraial do Cabo, Campos dos Goytacases, Niterói, Petrópolis e Rio de Janeiro.

4. Entre os anos de 1999 e 2002 cooperaram no projeto 12 universidades e instituições de pesquisa, a saber: a Universidade do Estado do Rio de Janeiro, a Universidade Federal do Rio de Janeiro, a Universidade do Estado do Norte Fluminense, a Universidade Santa Úrsula, a Universidade Federal Fluminense, a Pontifícia Universidade Católica do Rio de Janeiro, a Universidade do Rio de Janeiro, a Universidade Católica de Petrópolis, a Fundação Oswaldo Cruz, o Laboratório Nacional de Computação Científica, o Instituto de Estudos do Mar Almirante Paulo Moreira e o Instituto Nacional do Câncer.

Educ. Soc., Campinas, vol. 24, n. 83, p. 645-658, agosto 2003 
5. Entre 1999 e 2002, 606 estudantes e 341 pesquisadores participaram do projeto.

6. As autoras do artigo responderam pela formulação do projeto Jovens Talentos no âmbito da Secretaria de Estado de Ciência e Tecnologia (RJ), coordenando as suas ações desde seu início, em 1999, até 2002.

7. Sobre este tema consultamos Gomez \& Thedim-Costa (1999).

\section{Referências bibliográficas}

BERGER, P. Perspectivas sociológicas: uma visão humanística. Petrópolis: Vozes, 1986.

GOMEZ, C.; THEDIM-COSTA, S. Precarização do trabalho e desproteção social: desafios para a saúde coletiva. Ciência e Saúde Coletiva, São Paulo, v. 4, n. 2, p. 411-421, 1999.

LEVI, G.; SCMITT, C. (Org.). História dos jovens. São Paulo: Companhia das Letras, 1996.

MADEIRA, F.; RODRIGUES, E. Recado dos jovens: mais qualificação. In: JOVENS acontecendo na trilha das politicas públicas. Brasília, DF: CNPD, 1998. v. 2, p. 428-499.

MINAYO, M.C. (Org.). Fala, galera: juventude, violência e cidadania. Rio de Janeiro: Garamond, 1999.

SCHINDLER, N. Os tutores da desordem: rituais de cultura juvenil nos primórdios da era moderna. In: Levi, G.; SchmitT, C. (Org.). História dos jovens. São Paulo: Companhia das Letras, 1996.

\section{Fontes impressas}

Do Acervo de Documentos do Projeto Jovens Talentos/Fundação Centro de Ciências do Estado do Rio de Janeiro:

1. Quadros numéricos do projeto Jovens Talentos

2. Registro de atividades do estágio avançado (agosto de 2000 a agosto de 2001) 